\title{
Impact of a new cardiac magnetic resonance (CMR) program on management and clinical decision-making in cardiomyopathy patients
}

\author{
Siddique Abbasi ${ }^{1 *}$, Jaehoon Chung ${ }^{1}$, Geetha Bhat ${ }^{2}$, Ankit A Desai ${ }^{1}$, Thomas Stamos', Melissa Robinson Wood ${ }^{1}$, \\ Joan Briller ${ }^{1}$, George T Kondos ${ }^{1}$, Samuel Dudley ${ }^{1}$, Afshin Farzaneh-Far ${ }^{1,3}$
}

From 15th Annual SCMR Scientific Sessions

Orlando, FL, USA. 2-5 February 2012

\section{Summary}

We sought to evaluate the direct impact of a new CMR program on clinical management and decision-making in patients with cardiomyopathies from our established Heart Failure program.

\section{Background}

CMR provides unique diagnostic and prognostic information in patients with cardiomyopathies. Despite this, widespread uptake of CMR by Heart Failure physicians has been slow, particularly in the United States. In the current health care climate, routine use of a new imaging modality like CMR requires evidence for direct additive impact on clinical management.

\section{Methods}

This was a single-center registry from an academic medical center in the United States. The first 200 patients from a newly established CMR program were enrolled. All procedures were performed using standardized SCMR-recommended protocols on $1.5 \mathrm{~T}$ and $3 \mathrm{~T}$ scanners and interpreted by a Level 3 reader. Definitions for "significant clinical impact" of CMR were pre-defined and were collected directly from medical records and/or from patients. Categories of clinical impact included: new diagnosis, medication change, hospital admission/ discharge, as well as performance or avoidance of invasive procedures (angiography, revascularization, device therapy or biopsy).

${ }^{1}$ Division of Cardiology, University of Illinois at Chicago, Chicago, IL, USA Full list of author information is available at the end of the article

\section{Results}

No complications occurred and image quality was good in $96 \%$ of cases. Overall, $36 \%(n=75)$ of referrals were for assessment of cardiomyopathy (ejection fraction $<45 \%)$. All cardiomyopathy patients had a recent prior echocardiogram. In approximately two-thirds (63\%) of these patients, CMR had a significant impact on clinical management and decision-making. This included an entirely new diagnosis in $23 \%$ of cases and a change in medication management in $15 \%$. Anticoagulation was stopped in 5\% and started in 3\%. CMR results directly led to angiography in $7 \%$ and to the performance of percutaneous coronary intervention in $7 \%$. Bypass-surgery was performed in $4 \%$ and avoided in $9 \%$ directly as a result of CMR findings. Likewise, defibrillator placement was performed in $5 \%$ and avoided in $4 \%$.

\section{Conclusions}

CMR makes a significant impact on clinical management and decision-making in cardiomyopathy patients from an established Heart Failure program. It led to a significant change in clinical management in $63 \%$ of patients referred for assessment of cardiomyopathy. This additive impact was seen despite widespread use of echocardiography and other imaging tests in this patient group. This study lends support to the growing use of CMR by Heart Failure programs in the United States.

\section{Funding}

None.

\section{Author details}

'Division of Cardiology, University of Illinois at Chicago, Chicago, IL, USA. ${ }^{2}$ Center for Heart Transplant and Assist Devices, Advocate Christ Medical 
Published: 1 February 2012

doi:10.1186/1532-429X-14-S1-P144

Cite this article as: Abbasi et al:: Impact of a new cardiac magnetic resonance (CMR) program on management and clinical decisionmaking in cardiomyopathy patients. Journal of Cardiovascular Magnetic Resonance 2012 14(Suppl 1):P144.

Submit your next manuscript to BioMed Central and take full advantage of:

- Convenient online submission

- Thorough peer review

- No space constraints or color figure charges

- Immediate publication on acceptance

- Inclusion in PubMed, CAS, Scopus and Google Scholar

- Research which is freely available for redistribution

Submit your manuscript at www.biomedcentral.com/submit
() Biomed Central 